\title{
EVALUASI KESILAUAN LAMPU PENERANGAN LAPANGAN STADION BUMI SRIWIJAYA TERHADAP KUAT PENERANGAN LAMPU EKSISTING
}

\author{
M. Saleh Al Amin ${ }^{1}$, Emidiana $^{2}$, Nita Nurdiana ${ }^{3}$ \\ Prodi Teknik Elektro Universitas PGRI Palembang \\ Email : ${ }^{1}$ saleh.pgri@gmail.com, ${ }^{2}$ emidiana@ univpgri-palembang.ac.id, \\ nurdiana78@univpgri-palembang.ac.id
}

\begin{abstract}
ABSTRAK Sebuah Stadion Olahraga dapat digunakan untuk menggelar pertandingan sepak bola bertaraf Internasional, harus memiliki pencahayaan lapangan yang sesuai standar pertandingan internasional yaitu sebesar 1500 lux. Untuk memenuhi standar tersebut, lampu yang digunakan harus memiliki lumen dan daya yang besar. Pada lapangan Stadion Bumi Sriwijaya, penerangannya menggunakan lampu sorot eksisting dengan daya 2000 watt, dengan lumen lampu sebesar 200.000 lumen dimana. Penerangannya dibagi dalam 8 partisi dimana setiap partisi memerlukan lampu 30 buah sehingga jumlah total lampu yang harus dipasang sebanyak 240 buah lampu. Tiang lampu di tempatkan di keempat sudut lapangan, sehingga dibutuhkan sebanyak 60 lampu untuk setiap tiang dengan jumlah lampu eksisting sebanyak 35 buah.
\end{abstract}

Kata Kunci : Lampu Eksisting, Penerangan stadion, Kuat Penerangan

ABSTRACT A Sports Stadium can be used to hold international standard soccer matches, it must have a field lighting that matches the international match standards of 1500 lux. To meet these standards, the lamp used must have a large lumens and power. At the Bumi Sriwijaya Stadium field, the lighting uses an existing floodlight with 2000 watts of power, with 200,000 lumens of lamp lumen. The lighting is divided into 8 partitions where each partition requires 30 lamps so that the total number of lamps must be 240. The light poles are placed in the four corners of the field, so that as many as 60 lamps are needed for each pole with 35 existing lamps.

Key Word : Existing Lights, Field Lighting, Illumination

\section{PENDAHULUAN}

Stadion Bumi Sriwijaya dibangun pada tahun 1971. Bersama dua stadion lainnya yaitu Stadion Kamboja dan Stadion Patrajasa milik Pertamina, Bumi Sriwijaya merupakan salah satu stadion tertua di Palembang, pembangunannya rampung jelang pagelaran Pekan Olahraga Mahasiswa (POM) IX, yang merupakan POM terakhir sebelum berganti nama menjadi POMNAS (Pekan Olahraga Mahasiswa Nasional) [2] Stadion Bumi Sriwijaya merupakan sebuah stadion yang terletak di pusat keramaian kota Palembang, Sumatra Selatan, Indonesia. Stadion ini memiliki kapasitas 15.000 orang. Stadion Bumi Sriwijaya. Stadion ini juga dipergunakan untuk menggelar acara atletik, seperti pada Pekan Olahraga Nasional 2004 yang digelar di Sumatra Selatan. ${ }^{[5]}$ dan upacara pembukaan dan penutupan Islamic Solidarity Games 2013. Dalam kesehariannya, Stadion Bumi Sriwijaya digunakan sebagai arena bertanding oleh PS Palembang dan Sriwijaya FC U-21. Stadion ini juga beberapa kali digunakan sebagai tempat dihelatnya ajang besar seperti Pekan Olahraga Nasional (PON) XVI tahun 2004, pembukaan POMNAS XI tahun 2009, serta menjadi tempat digelarnya turnamen Islamic Solidarity Games (ISG) 2013 dan ASEAN University Games XVII tahun 2014.[6]

Stadion ini telah beberapa kali mengalami renovasi fisik, pada saat menjelang PON XI tahun 2004 di Palembang dan saat menjelang Sea Games tahun 2011 di Palembang.Tetapi renovasi yang telah dilakukan tersebut belum menjangkau standar penerangan untuk lapangan sepak bola 
Internasional, sehingga perlu untuk dilakukan renovasi untuk penerangan arena lapangan dengan standar Internasional.[1]

Stadion Bumi Sriwijaya Palembang merupakan stadion dengan sistem penerangan arena berupa sekelompok lampu sorot di setiap sidut lapangan, yang dipasang pada frame lampu yang disanggah menggunakan tiang lampu tunggal.

Di sini akan dilakukan evaluasi terhadap standar kesilauan lampu dan standar kuat penerangan (Lux) lampu bertaraf Internasional dibandingkan dengan kuat penerangan (Lux) lampu eksisting. Kuat penerangan (Lux) lampu eksisting adalah skitar 900 Lux, sedangkan untuk standar internasional minimal adalah 1.500 lux.

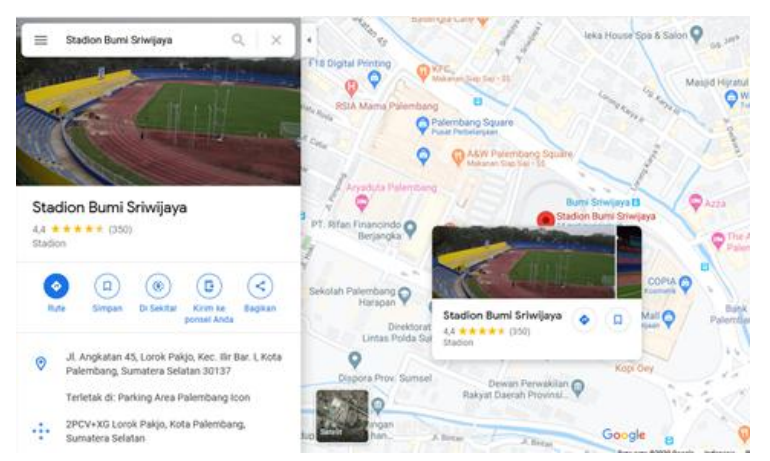

Gambar 1. Denah Lokasi Stadion Bumi Sriwijaya

\section{TINJAUAN PUSTAKA}

\section{Standar Sistem Penerangan}

Standar sistem penerangan diperlukan dalam perancangan sistem penerangan stadion agar menghasilkan kualitas penerangan yang baik dimana dapat memberikan keamanan, kenyamanan dan visualisasi yang sempurna. Perancangan sistem penerangan stadion dapat mengacu pada standar yang sudah diakui, seperti pada SNI 033647-1994 sebagai berikut[1][5]:

1. Tingkat penerangan horizontal pada arena 1 meter diatas permukaan lantai untuk ketiga kelas, sebagai berikut: (a) Untuk latihan dibutuhkan minimal 200 lux. (b) Untuk pertandingan dibutuhkan minimal 300 lux.

2. Untuk pengambilan video dokumentasi dibutuhkan minimal 1000 lux.

3. Penerangan buatan atau penerangan alami tidak boleh menimbulkan penyilauan bagi para pemain.

4. Pencegahan silau akibat matahari harus sesuai dengan SK SNI T-05-1989-F, Departemen pekerjaan Umum, tentang Tata Cara Penerangan Alami Siang hari untuk rumah dan gedung.

5. Sumber cahaya lampu harus diletakkan dalam satu area pada langit-langit sedemikian rupa sehingga sudut yang terjadi antara garis yang menghubungkan sumber cahaya tersebut dengan titik terjauh dari arena setinggi 1,5 meter garis horizontal nya minimal 300

6. Apabila gedung olahraga digunakan untuk menyelenggarakan lebih dari satu kegiatan cabang olahraga, maka untuk masing-masing kegiatan harus tersedia tata lampu yang sesuai untuk kegiatan yang dimaksud.

7. Masing-masing tata lampu harus merupakan instalasi yang terpisah saru dengan yang lainnya. 
8. Apabila menggunakan tata cahaya buatan, harus disediakan generator set yang kapasitas dayanya minimum $60 \%$ dari daya terpasang, generator set harus dapat bekerja maksimum 10 detik pada saat setelah aliran PLN padam.

\section{METODE PENELITIAN}

\section{Evaluasi Kesilauan dan Ketingguan tiang lampu.}

Berdasarkan standar kesilauan yang ditentukan, sudut cahaya lampu minimal membentuk sudut sebesar $25^{\circ}$ terhadap titik pinalti penjaga gawang dan lapangan secara mendatar, seperti pada gambar berikut :

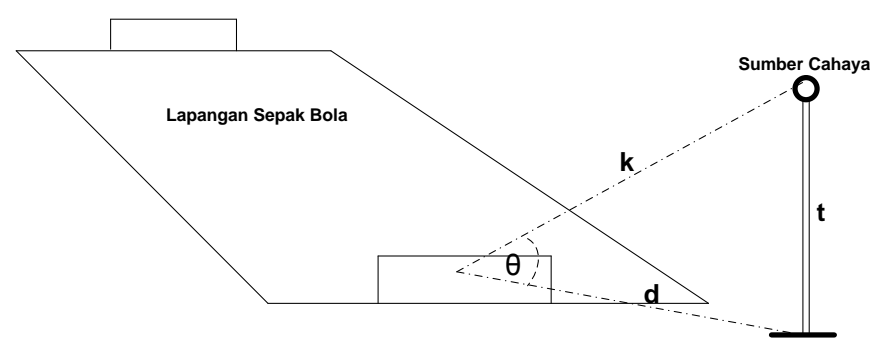

Gambar 2. Sudut cahaya terhadap bidang datar lapangan pada titik pinalti.

Keterangan gambar 1 :

$\mathrm{t}=$ Tinggi tiang lampu sorot.

$\mathrm{d}=$ Jarak mendatar titik tengah penjaga gawang terhadap tiang lampu sorot.

$\mathrm{k}=$ Jarak langsung titik tengah penjaga gawang terhadap lampu sorot.

$\theta=$ Sudut antara d dan $\mathrm{k}$.

Dengan ketentuan sudut minimal $25^{0}$ tersebut, secara tidak langsung akan berhubungan dengan tinggi tiang lampu, sehingga tinggi tiang lampu akan terkoreksi. [2]

Besarnya sudut $\theta$ yang diizinkan adalah : $25^{\circ}$, maka tinggi tiang lampu minimum adalah :

$$
\begin{aligned}
& \mathrm{t}=\mathrm{d} \cdot\left(\tan 25^{\circ}\right) \\
& \mathrm{t}=(0,4663) \cdot \mathrm{d}
\end{aligned}
$$

\section{Jumlah Luminer.}

Untuk membuat sistem penerangan lampu sorot menjadi merata di seluruh arena lapangan, maka dilakukan pembagian partisi lapangan menjadi beberapa bagian dengan luasan yang sama untuk setiap partisi, seperti gambar berikut :

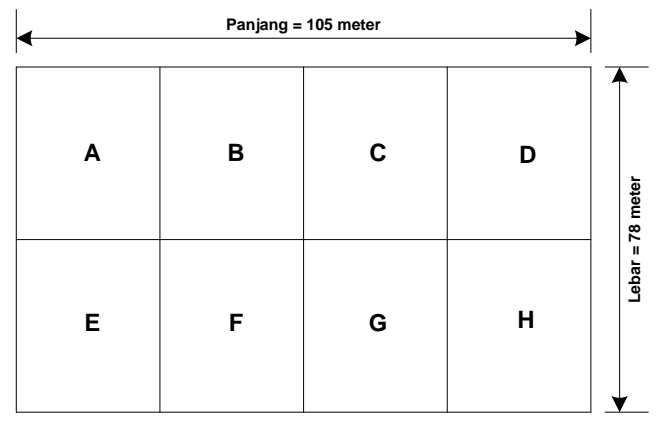


Gambar 3. Partisi lapangan sepak bola.

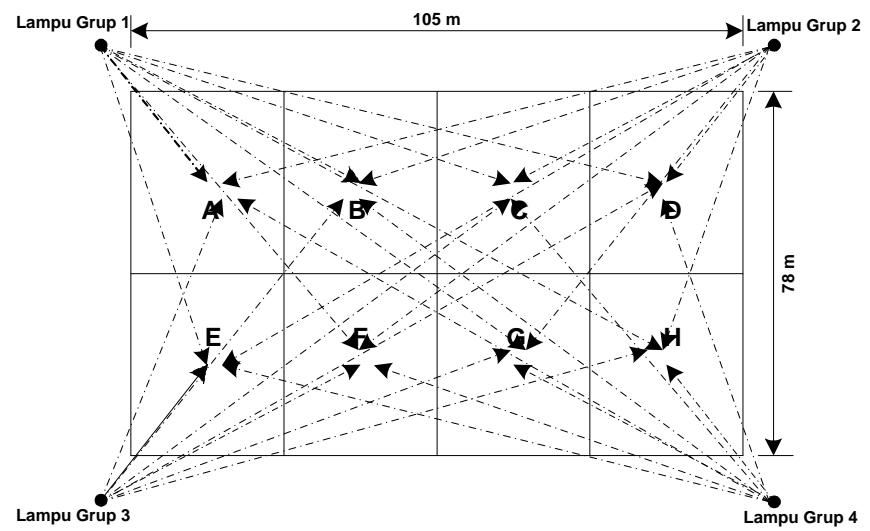

Gambar 4. Sebaran cahaya tiap partisi lapangan sepak bola.

Untuk menentukan banyaknya luminer di setiap partisi agar tercapai kuat penerangan (LUX) sesuai dengan standar, maka dilakukan metode perhitungan sebagai berikut :

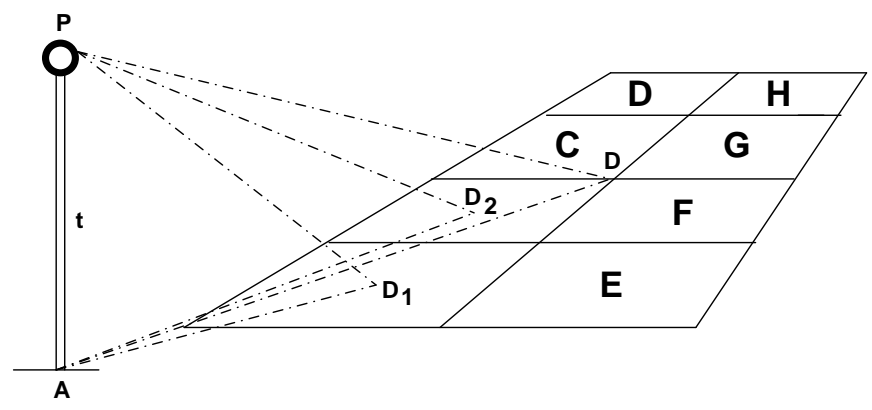

Gambar 5. Titik sebaran cahaya pada partisi A dan B.

Keterangan gambar 5 :

$\mathrm{AD}=$ Jarak horizontal rata-rata antara sumber cahaya terhadap pusat lapangan.

$\mathrm{PD}=$ Jarak nyata rata-rata sumber cahaya terhadap pusat lapangan.

\section{ANALISAN DAN PEMBAHASAN}

Dalam hal ini berdasarkan data lapangan diperoleh AD ditentukan dengan pengukuran langsung, atau dengan menggunakan alat bantu theodolit. $\mathrm{t}=\mathrm{AD} \cdot \operatorname{Cos} \theta$

Maka Jarak nyata rata-rata sumber cahaya terhadap pusat lapangan dapat ditentukan sebagai berikut :

$\mathrm{PD}=\sqrt{(t)^{2}+(A D)^{2}}$

Kuat penerangan pada titik pusat lapangan adalah : 


$$
\begin{aligned}
& \mathrm{E} \quad=\frac{I \cdot \cos \psi}{P D} \\
& \cos \psi=\frac{t}{P D}
\end{aligned}
$$

Lampu sorot yang digunakan eksisting adalah dengan daya 2000 watt, dengan lumen lampu sebesar 196.000 lumen, maka banyaknya luminer lampu sorot untuk setiap partisi adalah :

$\mathrm{N}=\frac{\phi}{\phi_{L}}$

Pada lapangan sepak bola Stadion gambar 2, dibagi menjadi 8 partisi, sehingga jumlah total lampu yang harus dipasang adalah sebanyak :

$\mathrm{N}_{\mathrm{T}}=8 \times \mathrm{N}$ buah

$\mathrm{N}_{\mathrm{T}} \quad=8 . \mathrm{N}$ buah lampu.

Karena terdapat 4 buah tiang lampu di setiap sudut lapangan, maka jumlah luminer lampu setiap tiang adalah :

$\mathrm{N}_{\mathrm{TT}}=\frac{8 . N}{4}=2 . \mathrm{N}$ buah.

Untuk perhitungan dengan peningkatan Lux lampu, maka untuk menentukan banyaknya luminer tambahan dapat dilakukan berdasarkan selisih Lux lampu antara Lux eksisting dengan Lux standar yang direkomendasikan, yaitu :

$\Delta \mathrm{E}=\operatorname{Lux}_{(\text {Rekomendasi) }}-\operatorname{Lux}_{(\text {eksisting })}$

\section{Tinggi Tiang Lampu.}

Berdasarkan ketentuan tingkat kesilauan yang diizinkan, tinggi tiang lampu membentuk sudut minimal $25^{0}$ terhadap jarak lampu sorot ke titik tengah penjaga gawang. Dari hasil pengukuran dan perhitungan diperoleh jarak mendatar titik tengah penjaga gawang terhadap tiang lampu sorot sebesar $\mathrm{d}=74,3 \mathrm{~m}$, dengan tinggi tiang lampu minimum sebesar $\mathrm{t}=34,6 \mathrm{~m}$. Direkomendasikan tinggi tiang minimum adalah $\mathrm{t}=35 \mathrm{~m}$.

\section{Jumlah Luminair.}

Berdasarkan standar pencahayaan buatan yang direkomendasikan, maka di rekomendasikan kuat pencahayaan di Stadion Bumi Sriwijaya sama dengan kuat pencahayaan di Stadion Bung Karno Jakarta yaitu sebesar 1.500 Lux, maka banyaknya lampu sorot yang dipasang dapat ditentukan sebagai berikut, dalam hal ini berdasarkan data lapangan diperoleh : $A D=98,99 \mathrm{~m}$ dengan $\mathrm{t}=35 \mathrm{~m}$, dengan jarak nyata rata-rata sumber cahaya terhadap pusat lapangan dapat ditentukan PD $=105 \mathrm{~m}$. Sehingga kuat cahaya pada titik pusat lapangan adalah :

$$
\begin{aligned}
& \mathrm{E}=\frac{I \cdot \cos \psi}{P D} \\
& \operatorname{Cos} \psi=\frac{t}{P D}
\end{aligned}
$$




$$
\begin{aligned}
& \operatorname{Cos} \psi=\frac{35}{105} \\
& \operatorname{Cos} \psi=0.3333
\end{aligned}
$$

Maka untuk setiap partisi, dengan $\mathrm{I}=$ 472.547,2547 Candela rata-rata kuat cahaya adalah $\phi=$ 5.935.193,519 lumen. Lampu sorot yang digunakan adalah dengan daya 2000 watt, dengan lumen lampu sebesar 200.000 lumen, maka banyaknya lampu sorot untuk setiap partisi adalah $\mathrm{N}=30$ buah.

Pada lapangan sepak bola Stadion Bumi Sriwijaya dibagi menjadi 8 partisi, sehingga jumlah total lampu yang harus dipasang adalah sebanyak $\mathrm{N}_{\mathrm{T}} \quad=240$ buah lampu. Karena terdapat 4 buah tiang lampu di setiap sudut lapangan, maka jumlah lampu setiap tiang akan dipasang sebanyak 60 buah, dengan jumlah lampu eksisting adalah : 35 buah.

\section{Kabel Feeder}

Yang dimaksud dengan kabel feeder di sini adalah dari panel LVMDP ke panel SDP lampu, menggunakan jenis kabel Under Ground dengan kapasitas sesuai dengan kebutuhan dayany. Ukuran diameter kabei yang digunakan harus mampu menahan besarnya beban yang dipikulnya, dalam hal ini adalah sejumlah lampu setiap tiang [4]

Beban listrik setiap tiang adalah :

- Daya setiap lampu = 2000 watt.

- Jumlah lampu setiap tiang = 60 unit.

Maka berdasarkan hasil perhitungan besarnya beban listrik yang merupakan jumlah daya total setiap tiang, yaitu : 60 x 2000 watt $=120.000$ watt. Dengan faktor keamanan diambil sebesar $25 \%$ (untuk mengatasi kejutan arus pada ballast saat start awal lampu), maka daya total beban yang harus dipikul oleh kabel adalah sebesar : $\mathrm{P}_{\mathrm{T}}=(1,25) \mathrm{x}(120.000)$ watt $=150.000$ watt.

Maka kabel feeder yang digunakan adalah : NYFGBY $(4 \times 95) \mathrm{mm}^{2}$

\section{Kabel Lampu}

Kabel lampu merupakan kabel penghubung dari panel SDP lampu ke titik lampu, maka besarnya beban yang harus dipikul kabel adalah sebesar :

- Tegangan lampu $=380$ volt (fasa-fasa)

- Daya tiap lampu = 2000 watt

Besarnya beban lampu yang harus dipikul oleh kabel, beserta kemampuan arus hubung singkat, adalah : $3 \mathrm{x}$ daya lampu $=6.000$ watt, maka kabel yang digunakan adalah $: \mathrm{NYY}(3 \times 4) \mathrm{mm}^{2}$ dengan ketebalan isolasi nominal adalah $1 \mathrm{~mm}$, untuk menahan gaya tarik dari ketinggian $36 \mathrm{~m}$.

\section{KESIMPULAN}

Dari penjelasan yang telah diberikan pada pembahasan dan perhitungan, dapat disimpulkan bahwa kuat penerangan lampu arena lapangan sepak bola stadion Bumi Sriwijaya Palembang eksisting belum mencapai standar Internasional, sehingga harus dilakukan renovasi penambahan kuat penerangan sesuai standar internasional, dengan terlebih dahulu dilakukan evaluasi secara menyeluruh terhadap kuat penerangan, dan penambahan jumlah lampu adalah sebanyak 25 buah 
lampu untuk setiap tiang, dan kabel feeder dan kabel lampu harus dilakukan penggantian untuk menopang daya lampu yang bertambah.

\section{DAFTAR PUSTAKA}

[1] A. Ghaffar, K. Karnoto, and A. Nugroho, "PERANCANGAN SISTEM PENCAHAYAAN BUATAN PADA LAPANGAN STADION UNIVERSITAS DIPONEGORO DENGAN MENGGUNAKAN DIALUX 4," Transient: Jurnal Ilmiah Teknik Elektro, vol. 6, no. 3, pp. 301-307, Nov. 2017. https://doi.org/10.14710/transient.6.3.301-307

[2] FootBall Tribe. (n.d.). Retrieved Februari 20, 2020, from https://footballtribe.com/indonesia/2017/09/21/bumi-sriwijaya-stadion-tua/

[3] P Van Harten, F Suryatmo :" Teknik Listrik Instalasi Penerangan / Instalasi Listrik Arus Kuat I", Penerbit Alumni Bandung.

[4] SNI 03-6197-2000 : "Konversi Energi Pada Sistem Pencahayaan"

[5] SNI 03-3647-1994, Tata cara perencanaan teknik bangunan gedung olahraga departemen pekerjaan umum. 1994.

[6] Stadion Bumi Sriwijaya. (n.d.). Retrieved Februari 2020, from Wikipedia.org:

https://id.wikipedia.org/wiki/Stadion_Bumi_Sriwijaya 